\title{
MACHADO DE ASSIS E EÇA DE QUEIRÓS: PARA ALÉM DA POLÊMICA...
}

Fátima Bueno

Universidade de São Paulo

São Paulo (SP), Brasil

\begin{abstract}
Resumo: Quando se pensa nas relações entre Machado de Assis e Eça de Queirós é comum referir-se à polêmica travada em torno da repercussão de $O$ primo Basílio no Brasil. Obviamente, vários outros aspectos podem ser considerados quando se propõe uma reflexão sobre diálogos possíveis entre os dois grandes autores das literaturas de língua portuguesa no século XIX. O nosso objetivo aqui é discutir como a presença do clero e a relação com a religião são retratadas, sobretudo, em duas obras desses escritores: Dom Casmurro e A relíquia.
\end{abstract}

Palavras-chave: Machado de Assis; Eça de Queirós; anticlericalismo.

\section{Machado de Assis and Eça de Queirós: beyond the controversy....}

Abstract: Whenever the relationship between Machado de Assis and Eça de Queirós is considered, it is usual to refer to the polemics revolving around $\mathrm{O}$ primo Basílio's reception in Brazil. However, many other aspects might be taken into consideration when one proposes to reflect about possible dialogues between the two major authors of the Portuguese language literatures. It is our goal to discuss how the presence of the clergy and and religious references are treated, mainly in two novels by these writers: Dom Casmurro and A relíquia.

Keywords: Machado de Assis; Eça de Queirós; anticlericalismo.

As polêmicas relações entre Eça de Queirós e Machado de Assis remontam, ao que tudo indica, ao ano de 1878, quando veio a lume $O$ primo Basílio e o escritor brasileiro publicou no jornal $O$ Cruzeiro a célebre crítica em que aponta os problemas estruturais que vê nos dois primeiros romances de Eça, os quais advêm, em sua opinião, principalmente da forma pueril como o escritor português incorpora os "tiques" da nova doutrina que, de maneira explícita, Machado repele: 
Ora bem, compreende-se a ruidosa aceitação d'O Crime do Padre Amaro. Era realismo implacável, consequente, lógico, levado à puerilidade e à obscuridade. Víamos aparecer na nossa língua um realista sem rebuço, sem atenuações, sem melindres, resoluto a vibrar o camartelo no mármore da outra escola que, aos olhos do Sr. Eça de Queirós, parecia uma simples ruína, uma tradição acabada. Não se conhecia no nosso idioma aquela reprodução fotográfica e servil das coisas mínimas e ignóbeis. Pela primeira vez, aparecia um livro em que o escuso e o - digamos o próprio termo, pois tratamos de repelir a doutrina, não o talento, e menos o homem - em que o escuso e o torpe eram tratados com um carinho minucioso e relacionados com uma exação de inventário. ${ }^{1}$

Apesar do alvo central da crítica ser $O$ primo Basílio, Machado de Assis aproveita o ensejo para acusar o $O$ crime do padre Amaro, cuja primeira edição em livro e segunda versão havia sido publicada publicada em 1876, de ser uma "imitação do romance de Zola, La faute de labbé Mouret", demonstrando conhecer as duas obras, ao comparar, em detalhes, ambos os enredos. Mas não fica só nisso. Acrescenta ainda que a maior originalidade do escritor português, a qual distancia o seu romance de La faute, consiste também no "maior defeito" na concepção do Crime: a reação de terror de Amaro, que o conduz ao assassinato do filho, diante da possibilidade de sua "falta" tornar-se pública:

Das duas forças que lutam na alma do padre Amaro, uma é real e efetiva - o sentimento da paternidade; a outra é quimérica e impossível - o terror da opinião, que ele tem visto tolerante e cúmplice no desvio dos seus confrades; e, não obstante, é esta a força que triunfa. Haverá aí alguma verdade moral? ${ }^{2}$

Obviamente, Eça de Queirós não fica indiferente a essa crítica e no prefácio da terceira versão de $O$ crime do padre Amaro, de 1880, que vinha publicando e reelaborando desde 1875, responde aos que, no Brasil e em Portugal, têm imputado ao seu livro a pecha de imitação do romance de Zola. Na apresentação desse "novo

1 ASSIS, Machado. Crítica. v.3 . Org. por Afrânio Coutinho. Rio de Janeiro: Editora Nova Aguilar, 1986. p. $903-913$ e 904.

2 Idem, p. 904. 
trabalho", responde à parte da crítica machadiana referente à acusação de plágio, sem, obviamente, explicitar o destinatário, afirmando que

Com conhecimento dos dois livros, somente uma obtusidade córnea ou má fé cínica poderia assemelhar esta bela alegoria idílica, a que está misturado o patético duma alma mística [o livro de Zola], a $O$ crime do padre Amaro que, como podem ver neste novo trabalho, é apenas, no fundo, uma intriga de clérigos e de beatas tramada e murmurada à sombra de uma velha Sé de província portuguesa. ${ }^{3}$

Não nos interessa aqui, ao partir da crítica machadiana, discutir a pertinência ou não da acusação de plágio de $O$ crime do padre Amaro. Mas não há como negar que o escritor brasileiro teve uma percepção bastante precisa do romance de Eça ao questionar a incongruência das atitudes de Amaro, se considerarmos o contexto social em que o personagem está inserido:

vive numa cidade de província no meio de mulheres, ao lado de outros que do sacerdócio só têm a batina e as propinas; vê-os concupiscentes e maritalmente estabelecidos, sem perderem um só átomo de influência e consideração. ${ }^{4}$

Machado parece ter razão. Se o romance de Eça é, como o próprio escritor português afirma, "apenas, no fundo, uma intriga de clérigos e de beatas", parecem excessivas, a princípio, as crises de Amaro e o temor da descoberta de seu caso com Amélia. De qualquer forma, o que nos interessa é refletir sobre o modo como os dois escritores retratam as respectivas sociedades em que estão inseridos, tendo em conta a presença intrínseca nelas de uma larga tradição cristã e a presença do clero, num século em que tanto a crítica ao cristianismo como também um acentuado anticlericalismo estiveram tão em voga.

No caso específico de Portugal, a importância da religião é bastante peculiar e está associada à formação da nacionalidade. Para Joel Serrão, a "religião cristã faz parte

3 QUEIRÓS. Eça. O crime do padre Amaro. In: Obra completa. v.1. Org. Beatriz Berrini. Rio de Janeiro: Editora Nova Aguilar, 1997. p. 89-437 e 100.

4 ASSIS, Machado de. Crítica. v.3 . Org. por Afrânio Coutinho, cit., p. 904. 
do património que Portugal herdou do passado quando se constituiu nação independente". 5 Inúmeros são os exemplos desse patrimônio, talvez um dos mais importantes seja a incorporação no imaginário cultural português da crença no milagre de Ourique, que sintetiza a ideia de eleição divina reservada ao país. Por outro lado, a constante presença do clero teve como contrapartida "um fenômeno social antiquíssimo, embora se tenha manifestado sob as mais variadas denominações. Em Portugal, pode-se dizer que o anticlericalismo data quase da fundação da nacionalidade" ${ }^{6}$ e tem "recuadas tradições literárias". 7

Esse processo se acentua no século XIX, já que, a partir da expansão das ideias iluministas e do advento do liberalismo, a tradição cristã é posta em xeque e a estreita participação do clero no âmbito do Estado e da cultura passa a ser mais duramente combatida. Essa perspectiva faz parte das indagações que vão mover a Geração de 70 em seu projeto ideológico de colocar Portugal em comunhão com a Europa culta. ${ }^{8}$ Talvez, por isso, o objetivo morigerante esteja subjacente à crítica anticlerical que está no primeiro plano do enredo de dois dos romances de Eça: no de estreia, $O$ crime do padre Amaro, e em A relíquia, de 1887. Esse mesmo objetivo já estava pressuposto na sua filiação ao realismo, tornada explícita na conferência feita em 12 de junho de 1871 , "A literatura nova (o realismo como nova expressão de arte)", no ciclo de palestras realizado nas salas do Cassino Lisbonense. Na sua intervenção, Eça defende a nova escola, contrapondo-a ao romantismo:

o romantismo era a apoteose do sentimento; o realismo é a anatomia do carácter. É a crítica do homem. É a arte que nos pinta a nossos próprios olhos - para nos conhecermos, para que saibamos se somos verdadeiros ou falsos, para condenar o que houver de mau na nossa sociedade. ${ }^{9}$

5 SERRÃO. Joel (Org.). Dicionário de História de Portugal. 4. v. Porto: Figueirinhas, 1971. p. 571.

6 Idem, p. 156.

7 MATOS, A. Campos (Org.). Dicionário de Eça de Queiroz. Lisboa, Caminho, 1988. p. 76.

8 Cf. QUENTAL, Antero. Causas da decadência dos povos peninsulares nos últimos três séculos. In:

Prosas sócio-políticas (Org. Joel Serrão). Lisboa: Imprensa Nacional - Casa da Moeda, 1982. p. 253-297.

9 QUEIRÓS, Eça. Eça de Queirós: a literatura nova (o realismo como nova expressão de arte). In: REIS,

Carlos. As conferências do Cassino. Lisboa: Alfa, 1990. p. 135-142. p. 140. 
Para o escritor português, portanto, tanto o tema como o modo de expô-lo fazem parte de um projeto de reforma social que o põe em consonância com sua geração.

Diferente, parece-nos, é o caso de Machado, que faz um retrato bastante crítico da sociedade brasileira oitocentista sem ser movido por uma perspectiva doutrinária ou de geração. Por esse motivo, a crítica anticlerical ou o questionamento da tradição cristã, apesar de não estarem no primeiro plano do enredo de seus romances, comparecem como parte do painel que traça dessa sociedade, já que é indiscutível tanto a presença do clero como da tradição cristã na cultura brasileira, no mínimo como parte de nossa herança lusitana.

Desse modo, não parece acidental que dois importantes protagonistas machadianos, Brás Cubas e Bento Santiago, tenham, em suas trajetórias iniciais de vida, a sombra de uma carreira religiosa. No caso do primeiro, essa possibilidade é cogitada pelo tio Ildefonso, então simples padre, como o descreve Brás Cubas, que prevê, para o sobrinho, uma carreira eclesiástica promissora:

Cônego é o que ele há de ser, e não digo mais por não parecer orgulho; mas não me admiraria nada se Deus o destinasse a um bispado... É verdade, um bispado; não é cousa impossível. Que diz você, mano Bento? ${ }^{10}$

Obviamente, o pai de Brás Cubas, que parece torcer o nariz para esse prognóstico, do mesmo modo que o faz em relação ao do outro tio, antigo oficial de infantaria, que vê no sobrinho "um certo olhar de Bonaparte", responde "a todos que [o filho] seria o que Deus quisesse". ${ }^{11}$

Aliás, se considerarmos o tio Ildefonso como lídimo representante do clero no romance, a sua caracterização revela uma superficialidade quanto aos valores mais

10 ASSIS, Machado. Memórias póstumas de Brás Cubas. In: Afrânio Coutinho. Rio de Janeiro: Editora José Aguilar, 1959. p. 409-549 e 426.

11 Idem, p.426. Podemos pensar que é muito irônico esse posicionamento do pai de Brás, já que, de fato, o seu "liberalismo" em relação à educação do filho, permite que, desde cedo, a sua alcunha seja a de "menino diabo", como pode ser visto no capítulo "O menino é pai do homem". Cf. ASSIS, Machado de. Memórias póstumas de Brás Cubas, cit., p. 427-429. 
profundos da filosofia religiosa. Tanto que se Brás Cubas o descreve como austero e puro, por outro lado acrescenta que

tais dotes, contudo, não realçavam um espírito superior, apenas compensavam um espírito medíocre. Não era homem que visse a parte substancial da Igreja; via o lado externo, a hierarquia, as preeminências, as sobrepelizes, as circunflexões. Vinha antes da sacristia que do altar. Uma lacuna no ritual excitava-o mais do que uma infração dos mandamentos. Agora, a tantos anos de distância, não estou certo se ele poderia atinar facilmente com um trecho de Tertuliano, ou expor, sem titubear, a história do símbolo de Niceia; mas ninguém, nas festas cantadas, sabia melhor o número e caso das cortesias que se deviam ao oficiante. ${ }^{12}$

Visão similar aparece em Dom Casmurro. O principal representante do clero neste romance é com certeza o padre Cabral. Ele não apenas ajuda a compor o quadro das relações sociais da família de Bentinho, como também tem uma dupla função: se adia a ida do personagem ao seminário, já que é o seu professor das primeiras letras, latim e doutrina, por sua vez a sua presença constante evoca à D. Glória o compromisso, assumido diante de Deus, de tornar o filho padre, caso este vingasse. O perfil desse padre não se distancia tanto do de tio Ildefonso. No capítulo que Bentinho dedica ao título que Cabral recebe, "O protonotário apostólico", o excesso de fatuidade ressalta na descrição do comportamento do padre, o que se complementa com a nada apostólica gula, que também o caracteriza:

buscava um assunto alheio para se mostrar esquecido da própria glória, mas era esta que o deslumbrava na ocasião. Era um velho magro, sereno, dotado de qualidades boas. Alguns defeitos tinha; o mais excelso deles era ser guloso, não propriamente glutão; comia pouco, mas estimava o fino e o raro, e a nossa cozinha, se era simples, era menos pobre que a dele. Assim, quando minha mãe lhe disse que viesse jantar, a fim de se lhe fazer uma saúde, os olhos com que aceitou seriam de protonotário, mas não eram apostólicos. E para agradar a minha mãe novamente pegou em mim, descrevendo o meu futuro eclesiástico, e queria saber se ia para o seminário agora, no ano

12 Idem, p.428. 
próximo, e oferecia-se a falar ao "senhor bispo", tudo marchetado do "protonotário Santiago." ${ }^{13}$

De modo diverso do destino de Brás Cubas, cujo pai descarta qualquer imposição que predetermine o futuro do filho, em Dom Casmurro Bento é, como ele próprio diz, destinado $a b$ ovo à vida religiosa, em função da promessa feita pela mãe. Mais que isto. Um dos grandes conflitos que mobilizam o protagonista, e que aparece no início da sua evocação do passado, é a ameaça que esse destino representa para seu futuro amoroso, após a denúncia de José Dias. Ou seja, se apenas furtivamente Brás Cubas teve associado ao seu destino a carreira religiosa, toda a educação de Bentinho estará mobilizada para esse fim.

No entanto, se atentarmos para a forma como o personagem vai se revelando, é possível observar que sua relação com a religião também se dá de modo superficial. Isto fica visível no modo como Bento manipula as inúmeras promessas que faz, e quase sempre não cumpre, e que ele esmiúça no capítulo XX, "Mil padres-nossos e mil avemarias":

\begin{abstract}
Desde pequenino acostumara-me a pedir ao céu os seus favores, mediante orações que diria, se eles viessem. Disse as primeiras, as outras foram adiadas, e à medida que se amontoavam iam sendo esquecidas. Assim cheguei aos números vinte, trinta, cinquenta. Entrei nas centenas e agora no milhar. Era um modo de peitar a vontade divina pela quantia das orações; além disso, cada promessa nova era feita e jurada no sentido de pagar a dívida antiga. Mas vão lá matar a preguiça de uma alma que a trazia do berço e não a sentia atenuada pela vida! O céu fazia-me o favor, eu adiava a paga. Afinal perdi-me nas contas. ${ }^{14}$
\end{abstract}

As causas dessa intensa barganha variam desde o desejo de solução dos problemas mais banais - para que não chovesse e o passeio previsto para certa tarde não fosse cancelado, por exemplo -, até o caso de uma crise que para Bento é "gravíssima" (e não resisto aqui a não parodiar o estilo superlativo de José Dias), como no capítulo em questão: em que a iminência da ida para o seminário, além de incompatível com sua 
falta de vocação, representa o afastamento de Capitu, que passa a ocupar, desde a denúncia, o centro de todos os seus desejos. Entretanto, por mais que Bento seja, a princípio, moldado por uma formação católica, e que a promessa de D. Glória antecipe os valores sob os quais o filho será criado, desde a infância a sua relação com a religião está ligada à satisfação de seus desejos pessoais, mais ou menos comezinhos, mas que não têm nenhuma perspectiva que conduza a uma elevação espiritual e transcendente, valores que estão, por princípio, associados ao espírito religioso.

De fato, a religiosidade de Bento é bastante relativa. Dois capítulos são exemplares de seu comportamento: o que se intitula "Um pecado" e o seguinte, "Adiemos a virtude". No primeiro, chega a cogitar que a morte da mãe poderia ser a solução de seus problemas: "Mamãe defunta, acaba o seminário". Imediatamente a seguir, se mostra mobilizado pelo remorso:

Leitor, foi um relâmpago. Tão depressa alumiou a noite, como se esvaiu, e a escuridão fez-se mais cerrada, pelo efeito do remorso que me ficou. Foi uma sugestão da luxúria e do egoísmo. A piedade filial desmaiou um instante, com a perspectiva da liberdade certa, pelo desaparecimento da dívida e do devedor, foi um instante, menos que um instante, o centésimo de um instante, ainda assim o suficiente para complicar a minha aflição com um remorso. ${ }^{15}$

O comportamento de Bento parece sugerir arrependimento diante da infração cometida, a ponto de prometer rezar dois mil padre-nossos, se Deus o perdoasse e salvasse a vida da mãe. Mas vimos que o que o caracteriza é o não cumprimento das promessas feitas; ou seja, efetivamente ele não salda os compromissos que assume. Mais que isto. No capítulo seguinte, "Adiemos a virtude", ele sugere que uma boa ação possa servir de compensação a seus maus pensamentos; entretanto, o exemplo que dá de má ação, por causa de uma dor de cabeça desejar que o trem da central estourasse longe dos seus ouvidos, mesmo que morresse alguém, não pode ser compensado pela boa ação que realiza no dia seguinte: a de perder o mesmo trem por ter ido socorrer com sua bengala a um cego que não tinha bordão. ${ }^{16}$ Nem na justiça do céu, nem na dos homens, esta ação compensaria a morte de alguém. Apesar de ele equiparar um ato efetivamente 
realizado a um simples desejo, é preciso insistir que isso não deveria atenuar a transgressão que cometeria caso tivesse o poder de tornar realidade o que desejou. De fato, o que está no cerne desse comportamento de Bento, e que ele explicita ao revelar as suas fantasias mais íntimas, é que, se ele tivesse poder para torná-las reais, não hesitaria em causar a morte dos que representassem empecilho para a satisfação de seus desejos.

No entanto, o que o caracteriza é a inação. Ele quase chega a partir para o ato quando oferece a Ezequiel o café envenenado que havia preparado para si próprio. Obviamente, a distância entre a intenção e o gesto é o que o separa, pelo código de leis que rege nossa sociedade, da figura do criminoso. Todavia, o personagem não passa, pelo menos no caso de seu relacionamento com Ezequiel, pelas etapas necessárias para a concessão do perdão: remorso, arrependimento, confissão e penitência, passos imprescindíveis, segundo as regras do catolicismo, para o perdão dos pecados e reconciliação com Deus. Isto fica mais evidente nos capítulos em que torna a reencontrar Ezequiel, já adulto, e no que narra a morte do filho:

Comigo disse que uma das consequências dos amores furtivos do pai era pagar eu as arqueologias do filho; antes the pegasse a lepra... ${ }^{17}$

Não houve lepra, mas há febres por todas essas terras humanas, sejam velhas ou novas. Onze meses depois, Ezequiel morreu de uma febre tifoide. $^{18}$

Quase no final do romance, no capítulo em que Bento revela a Capitu não acreditar que Ezequiel seja seu filho, esta lhe diz:

Sei a razão disto; é a casualidade da semelhança... A vontade de Deus explicará tudo... Ri-se? É natural; apesar do seminário, não acredita em Deus; eu creio... Mas não falemos nisto; não nos fica bem dizer mais nada. ${ }^{19}$ 
A observação de Capitu é bastante pertinente, pois à medida que o personagem vai se revelando diante do leitor o que se sobressai é que suas relações com a fé e com Deus vão se adequando aos seus próprios desejos e conveniências. Para John Gledson, o Deus de Bento é "burilado à imagem dele". ${ }^{20} \mathrm{E}$ Bentinho, não muito diferente de outro protagonista machadiano, Brás Cubas, parece também ser movido pelo egoísmo e pela luxúria. Afinal, foram esses sentimentos que para ele justificaram ter desejado, por exemplo, a morte da mãe. Mas por enquanto vamos ficando por aqui e retomemos Eça de Queirós.

No capítulo XIII de Viagens na minha terra (1846), Almeida Garrett faz o seguinte comentário: "Já me disseram que eu tinha génio frade, que não podia fazer conto, drama, romance sem lhe meter o meu fradinho." Após esse comentário, começa a contabilizar os frades do conjunto de sua obra, até concluir:

Pois senhores, não sei que lhes faça; a culpa não é minha. Desde mil cento e tantos que começou Portugal, até mil oitocentos e trinta e tantos que dizem que ele se restaurou, outros que o levou a breca, não sei o que se passasse ou pudesse passar nesta terra, coisa pública ou particular, em que o frade não entrasse. ${ }^{21}$

A pertinência irônica do comentário vem reforçar o quadro que descrevemos do país. O que Garrett aponta e denuncia, ao mesmo tempo, é que para retratar a sociedade portuguesa é necessário falar do clero que, desde a formação de Portugal, está metido tanto no espaço público como no privado. Por esse motivo, talvez, é que o enredo do romance de estreia de Eça de Queirós se estruture a partir do universo clerical, ainda que escrito cerca de trinta anos após a novela de Garrett. Mas o que nos interessa agora trazer para discussão é um outro romance do escritor, publicado em 1887, A relíquia, cujo título já antecipa que a história está interligada à tradição cristã e, inevitavelmente, contará também com representantes do clero.

Narrado em primeira pessoa, como Dom Casmurro, a vida de Teodorico Raposo será também profundamente marcada por uma perspectiva religiosa. Mesmo o

20 GLEDSON, John. Machado de Assis: impostura e realismo. Uma reinterpretação de Dom Casmurro. São Paulo: Companhia das Letras, 1991. p. 143.

21 GARRETT, Almeida. Viagens na minha terra. Porto: Caixotim, 2004. p. 145-146. 
rapaz não sendo destinado à carreira eclesiástica, a tia Patrocínio, responsável pela educação do sobrinho após a orfandade, imporá a ele uma série de valores que pauta numa visão peculiar que tem da fé. Donzela, velha e ressequida, como Teodorico a descreve, Patrocínio tem horror a qualquer forma de amor que não seja o ascético:

E não lhe bastava reprovar o amor como cousa profana; a senhora dona Patrocínio das Neves fazia uma carantonha, e varria-o como coisa suja. Um moço grave, amando seriamente, era para ela "uma porcaria!" Quando sabia de uma mulher que tivera um filho, cuspia para o lado, rosnava - "que nojo!" E quase achava a Natureza obscena por ter criado dois sexos. ${ }^{22}$

É ela que, como D. Glória em relação a Bentinho, representa o maior obstáculo para a vida afetiva e sexual do sobrinho. Afinal, deixa claro, repetindo

todos os dias, com os dentes rilhados, [e referindo-se a Teodorico] que se uma pessoa do seu sangue, e que comesse o seu pão, andasse atrás de saias, ou se desse a relaxações, havia de ir para a rua, escorraçado a vassoura, como um cão. ${ }^{23}$

Obviamente, há uma distância na estrutura dos dois romances quanto à forma como o universo religioso intervém na vida dos dois protagonistas. No caso do romance de Eça, esse universo é retratado de maneira muito mais caricata. Todavia, tanto Bento como Teodorico precisam encontrar estratégias de saída em relação a essas duas mulheres que representam empecilhos concretos para o direito de ambos à própria vida sexual. Teodorico também tem interesse na fortuna da tia, já que tem como rival, na disputa pela herança, Jesus Cristo e seus representantes na terra: as ordens religiosas e os padres que volitam em torno dela. Por isso, manifesta inúmeras vezes o desejo que a tia "rebente", pois sua morte lhe garantiria tanto a estabilidade financeira quanto o direito de exercer livremente a sua sexualidade.

22 QUEIRÓS. Eça. A relíquia. In: Obra completa. v.1. Org. Beatriz Berrini. Rio de Janeiro: Editora Nova Aguilar, 1997. p. 839-1033 e 867.

23 Idem, p. 868. 
Vimos que Bento faz inúmeras promessas na expectativa de ter seus desejos, mesmo que banais, atendidos, e que chega a desejar, como saída para não se tornar padre, a morte da própria mãe; Teodorico, por sua vez, faz peregrinações pelas igrejas de Lisboa, se ajoelha no altar da casa da titi, pedindo que os céus intervenham a seu favor, livrando-o da tia e para que possa cair novamente nas graças de suas ex-amantes. Ou seja, suas penitências e orações são motivadas também pelo egoísmo e pela luxúria, como ocorre com o protagonista machadiano. Entretanto, a diferença crucial entre Raposão e Bentinho é que o personagem brasileiro parece censurar a si próprio por esses comportamentos, enquanto Teodorico não demonstra nem arrependimento, nem censura moral. Aliás, no final do romance, ele apenas se lamenta por não ter sido hipócrita o bastante para sustentar as suas mentiras, pois assim não teria caído em desgraça e ficado fora do testamento da tia.

No prólogo de A relíquia, Teodorico diz que decidiu escrever as suas memórias por considerar que sua vida encerra uma lição lúcida e forte. Duas são, entretanto, as lições que parece legar ao seu leitor: uma delas, que constitui a mensagem com que encerra o livro, é que lhe faltou "o descarado heroísmo" de levar às últimas consequências a sua hipocrisia, pois, caso o tivesse feito, seria aclamado pela Igreja e pela Ciência e herdaria todos os bens da tia. ${ }^{24}$ A outra lição que parece legar é, paradoxalmente, reconhecer a "inutilidade da hipocrisia". É o momento também em que admite a sua descrença em relação ao cristianismo:

Consultei a minha consciência, que reentrara dentro de mim - e bem certo de não acreditar que Jesus fosse filho de Deus e de uma mulher casada de Galileia (como Hercules era filho de Júpiter e de uma mulher casada da Argólida) - cuspi de meus lábios, tornados para sempre verdadeiros, o resto inútil da oração. ${ }^{25}$

Se Bento não responde a Capitu, nem comenta a constatação a que ela chega de que, apesar do seminário, ele não acredita em Deus -, Teodorico vai além, negando a existência do divino. 
Como vimos, há proximidades e divergências na maneira como os protagonistas de A relíquia e Dom Casmurro se relacionam com a religião. O mesmo se dá em relação à forma como o clero aparece nas duas sociedades retratadas. No caso de romance machadiano, no famoso capítulo da denúncia, José Dias imagina que a carreira eclesiástica possa conduzir Bentinho a "altos destinos", já que "o clero ainda tem grande papel no Brasil". ${ }^{26} \mathrm{O}$ uso do advérbio "ainda" marca bem que a nossa realidade nos diferencia das sociedades contemporâneas que, desde a revolução francesa, vêm redimensionando o papel do clero na sociedade civil.

Diferente parece ser o caso português, já que, se tomarmos como parâmetro o O crime do padre Amaro, fica evidente que a importância do clero em Portugal está reduzida a sua atuação fora dos grandes centros do país. Tanto que Eça focaliza o desenvolvimento da trama na província, "à sombra da Sé de Leiria", enquanto José Dias lembra que "um bispo presidiu a Constituinte, e o padre Feijó governou o Império", ${ }^{27}$ ou seja, que no Brasil o clero ainda tem estofo para intervir nos rumos da nação.

Apesar das diferenças entre os dois contextos sociais, ambos os escritores se aproximam, ao mostrar de maneira bastante crítica a classe sacerdotal, seja através da sua subordinação a um universo centrado no feminino (lembro aqui que Machado, ao criticar o Crime, realça que Amaro "vive numa cidade de província no meio de mulheres", e ele próprio mostra, em Dom Casmurro, a rede social gravitando em torno de D. Glória, a beata, carola, papa-missas, como diz Capitu), seja através do perfil, em geral medíocre, com o qual esse clero acaba por ser configurado nas obras dos dois autores.

No caso de Eça, é preciso salientar que a denúncia do comportamento lascivo do clero aparece no primeiro plano em $O$ crime do padre Amaro e tem destaque em $A$ relíquia. Afinal, o padre Negrão herda não apenas boa parte dos bens da tia de Teodorico, como também a Adélia, uma de suas amantes da juventude. Talvez o destaque que ganhe, nas obras de escritores portugueses, o comportamento lascivo dos padres, seja pelo fato de que, entre as recuadas tradições literárias do anticlericalismo em Portugal, encontra-se a que denuncia a luxúria da clerezia como incompatível com

26 ASSIS, Machado de. Dom Casmurro, cit., p. 732.

27 Idem, p. 732. 
valores espirituais e a prática do celibato que, segundo as leis da Igreja Católica, deveria pautar a vida de seus representantes. ${ }^{28}$

De qualquer modo, independente da realidade particular de cada país e das diferenças estilísticas dos escritores dos quais estamos tratando, ambos são fundamentais no retrato que fazem das sociedades portuguesa e brasileira do Oitocentos, e, ainda hoje, suas obras servem de baliza para nossas reflexões.

Camilo Castelo Branco, comentando a estreia de Eça na literatura portuguesa com o romance $O$ crime do padre Amaro, prognosticava: "Admirável. Obra-prima que há-de resistir como um bronze a todas as evoluções destruidoras das escolas e da moda". ${ }^{29}$ Parece que Camilo previu bem. Afinal, o interesse pelas obras de Eça de Queirós e de Machado de Assis permanece e os temas por eles tratados não perderam o vigor e continuam, de algum modo, atuais nos dias de hoje, ultrapassando realmente as evoluções destruidoras das escolas e da moda.

Referências:

ASSIS, Machado de. Memórias póstumas de Brás Cubas. In: Obra Completa. (Org. Afrânio Coutinho). Rio de Janeiro: Editora José Aguilar, 1959. v.1. p. 409-549.

ASSIS, Machado. Dom Casmurro. In: Obra Completa. (Org. Afrânio Coutinho). Rio de Janeiro: Editora José Aguilar, 1959. v. 1. p.727-870.

ASSIS, Machado. Crítica. In: Obra completa. (Org. Afrânio Coutinho). Rio de Janeiro: Nova Aguilar, 1986. v. 3.

GLEDSON, John. Machado de Assis: impostura e realismo - uma reinterpretação de Dom Casmurro. São Paulo: Companhia das Letras, 1991.

MATOS, A. Campos (Org.). Dicionário de Eça de Queiroz. Lisboa: Caminho, 1988.

28 Basta conferir em inúmeras cantigas de escárnio e mal dizer, como também em vários autos vicentinos, como a denúncia ao comportamento lascivo do clero português faz parte das recuadas tradições do anticlericalismo no país.

29 Cf. Castelo Branco, in: MATOS, A. Campos (Org.). Dicionário de Eça de Queiroz. 2. ed., rev. e aum. Lisboa: Caminho, 1993. p. 244. 
QUEIRÓS. Eça de. O Crime do padre Amaro. In: . Obra Completa. (Org. Beatriz Berrini). Rio de Janeiro: Nova Aguilar, 1997. v. 1, p.89-437.

QUEIRÓS, Eça de. A literatura nova (o Realismo como nova expressão de arte). In: REIS, Carlos. As conferências do Casino. Lisboa: Alfa, 1990. p.135-142.

QUENTAL, Antero. Causas da decadência dos povos peninsulares nos últimos três séculos. In: . Prosas sócio-politicas. (Org. Joel Serrão). Lisboa: Imprensa Nacional - Casa da Moeda, 1982. p.253-297.

SERRÃO. Joel (Org.). Dicionário de História de Portugal. Porto: Figueirinhas, 1971. 4 $\mathrm{V}$.

Fátima Bueno é professora da USP desde 2003 e defendeu a tese de livre docente, Figurações da história na literatura portuguesa, em 2010. É coorganizadora de Literatura portuguesa - história, memória e perspectivas (2007). Tem artigos e capítulos de livros publicados em diversos periódicos do país (Via Atlântica, Tempo Brasileiro) e do exterior. Sua publicação mais recente é "Eça no cinema: El crimen del padre Amaro (2002)", capítulo do livro Avanços em literatura e cultura portuguesas de Eça de Queirós a Fernando Pessoa. Santiago de Compostela - Faro: 2012. E-mail: <fabueno@usp.br>

Recebido: 03/09/2012

Aprovado: 19/11/2012 